\title{
Customer Experience Project: A Framework to Create and Deliver Value to Customers
}

\author{
Edson Coutinho Da Silva ${ }^{1}$ \\ ${ }^{1}$ University Centre FEI, São Bernardo do Campo, São Paulo, Brazil \\ Correspondence: Edson Coutinho Da Silva, University Centre FEI, São Bernardo do Campo, São Paulo, Brazil. \\ E-mail: dr.edson.coutinho@gmail.com
}

Received: July 18, 2021 Accepted: August 20, $2021 \quad$ Online Published: August 26, 2021

doi:10.5539/ijms.v13n3p21 URL: https://doi.org/10.5539/ijms.v13n3p21

\begin{abstract}
This theoretical paper aims to approach the major customer value drivers and then, describe the main five stages required to support customer experience (CX) professionals in order to conceive, design and implement CX improvement projects. The CX focuses on customer's perceptions and related feelings caused by the one-off and cumulative effect of interactions with a supplier's employees, systems, channels, or products. The CX encompasses every interaction the customer has with an organisation throughout the customer lifecycle through multichannel. Generally speaking, providing a good experience can affect and impact customer satisfaction, loyalty, and engagement. Business companies recognised the competitive advantage of $\mathrm{CX}$ and the value creation reside not only in what a company delivers for its customers but in how it delivers products and services. Therefore, a positive CX requires coordination across different functions within an organisation, for instance, marketing, product or service development, customer care, operations, or retail branches.
\end{abstract}

Keywords: customer experience, customer value, customer journey, service design, framework

\section{Introduction}

The customer experience (CX) has encouraged a new sort of competition. Providing a good experience influences and impact customer satisfaction, the building of customer loyalty, manage customer's expectations, instilled confidence, supported the brand and, also generates emotional bonds with customers or, conversely, leads to emotional scarring (Lin \& Bennett, 2014). Besides, CX focuses on creating a differentiated experience at touchpoints that customers prefer to interact with a particular company. Focusing on CX as a strategy supports service delivery capabilities adjust and adapt to behavioural shifts of the target audience (Nasution et al., 2011). Benefits accomplished go well beyond improvements in customer satisfaction and churn. Loyal customers buy more and share experiences with their reference groups, for instance, family and friends (Berry \& Carbone, 2007). For Johnston and Kong (2011), experience also helps generate cumulative sales through recommendations on social and professional networks. In other words, business companies have recognised the competitive advantage of $\mathrm{CX}$ and the value that consists not only in what an organisation delivers for its customers but in how it delivers products and services.

Managing CX can be complex and challenging because every touchpoint can affect customer perception and loyalty. Then, to influence those interactions, organisations often need to go through a significant transformation of their own, for example, adapting their systems, processes, and infrastructure to create or adopt a customer-centred approach to support the business platform (Kim, Kim, \& Miner, 2009). However, it seems that the effort is worth the investment. Positive CX can build its momentum, creating an "ecosystem of goodwill" that cost relatively little to maintain but can deliver a loyal customer base that generates tangible bottom-line returns. Although many departments and functions have systems to track customer data, few organisations have a holistic, enterprise-wide view of CX. According to a study designed by KPMG (2019), there are six major axes that companies need to focus on $\mathrm{CX}$ projects:

a) Integrity, a reliable and robust $\mathrm{CX}$ project.

b) Expectations met the customer needs.

c) The resolution, make the customers feel good about the experience.

d) Time and effort, remove unnecessary obstacles, impediments and bureaucracy. 
e) Personalisation, the key component of most experience, includes individualised attention, knows preferences and creates an experience that feels personal.

f) Empathy, the emotional capacity to show customer understanding about a given experience.

Thus, the CX is the customers' holistic view of their experience with the business, brand, product, and service. CX is different from customer service. By and large, customer service is just one side of the entire CX. Comparatively, CX is a customer's global view of the business, based on their interaction with it, whereas customer service refers to particular touchpoints within the experience where a customer demands and receives assistance or help (Brakus, Schmitt, \& Zarantonello, 2009). Under these circumstances, CX is larger than customer service because it includes every touchpoint a customer ever has with the business, whether it is the moment they first contact, all the way through the time they call the customer service professionals to complain about the product or service (Grace \& O'Cass, 2004).

Thus, design thinking, service design, customer personas, empiricism, interactions, empathy mapping, stakeholder mapping, customer journey, prototyping, so forth are embraced in the CX project glossary. Then, considering a CX project, how to approach the customer value drivers and assist CX professionals in conceiving, design and implement CX improvement projects? This theoretical article aims to approach the major customer value drivers and then describe the primary five stages required to assist $\mathrm{CX}$ professionals in conceiving, design and implement CX improvement projects.

\section{What Is CX?}

The concept of CX was first approached in the 1980s by Holbrook and Hirschman (1982). They were studying the perception of consumption experience and hedonic consumption. Since the 1990s, Carbone and Haeckel (1994) and Pine and Gilmore (1998) have popularised the expression CX in marketing literature. In the 2000s, Gentile, Spiller and Noci (2007) evolved the concept of CX, including the interactions between customer and product (or service) as a significant element for creating an experience. Further, they added the personal experience with customer's involvement at distinct approaches, including rational, sensory, physical, emotional, and spiritual. Then, the intensity of the CX was established by one or more of these dimensions. Walls et al. (2011) state that experiences are personal and exceptional; they encompass customers perceptions and participation, engage customers emotionally, shared with others and are remembered for a while. The CX is particularly relevant for services. Pine and Gilmore (1999) state four dimensions of CX: entertainment, aesthetic, education, and escapism.

The literature of marketing, retailing and service management historically has not considered CX as another construct. Instead, researchers have focused on measuring customer satisfaction and service quality (Parasuraman, Zeithaml, \& Malhotra, 2005; Verhoef et al., 2009). Nevertheless, it is not that CX has never been observed. Most likely, Holbrook and Hirschmann (1982) theorised that consumption has experiential attributes. Schmitt (1999) has explored how organisations design experimental marketing by having customers sense, feel, think, act, and relate to the organisation and its brands. Berry, Carbone and Haeckel (2002) suggest that for the organisation to compete by offering customers a satisfactory experience, they should orchestrate all the "clues" that individuals detect in the buying process. Thus, satisfaction or dissatisfaction is an essential outcome of CX. Despite scarce empirical evidence, marketers seem to agree with a conceptual distinction between CX and satisfaction.

Schmitt (2003) categorically pointed out that satisfaction is an outcome-oriented attitude-based on CX - whereas experience is a process-oriented concept. Puccinelli et al. (2009) also supported Schmitt's (2003) point of view. Equally, Meyer and Schwager (2007) recommended that customer satisfaction is the accumulation of a sequence of CX, where the degree of satisfaction is the net outcome — or liquid result — of good experiences minus bad experiences. Similarly, Rowley (1999), in her work, states that total experience is a whole concept, which is a role of customer satisfaction derived from different aspects of the transaction. However, Maklan and Klaus (2011) noticed experience and expectation as significant predictors of satisfaction. Customers who have negative attitudes would evaluate satisfaction negatively. The relationship between CX and satisfaction has been approached in the marketing literature. For Berry and Carbone (2007), the favourable the experience is the higher satisfaction.

In effect, the $\mathrm{CX}$ emerges from a set of communications between a customer and a product, a business, or part of its organisation, which raise a reaction (Gentile, Spiller, \& Noci, 2007). But CX is also customers' internal and subjective attitude to direct or indirect contact with a given organisation. On the one hand, direct contact generally happens in the purchase, use, and service and is usually initiated by the customer. On the other hand, indirect contact most often includes unplanned encounters with representatives of an organisation's product, 
service or brands. It takes the form of word-of-mouth suggestions or criticisms, advertising, news reports, reviews and so forth (Kuehnl, Jozic, \& Homburg, 2019). In addition, the CX construct encompasses a holistic and includes the customer's cognitive, affective, emotional, social, and physical attitudes to the organisation. Under these circumstances, a CX provides the total experience, in other words, the search, purchase, consumption, and after-sale phases of the experience, and can encompass multiple channels (Barwitz \& Mass, 2018).

The CX embraces every communication the customer has with an organisation throughout the customer lifecycle, whether in-person, over the phone, or online. At the centre of good CX is a clear and compelling value proposition, that is, a product or service that satisfies a customer's need or want, usually associated with a short or long-term goal (Epp \& Price, 2011). Furthermore, delivering a positive CX generally requires coordination across different functions within an organisation, such as marketing, product development, customer care, operations, or retail branches. Hence, what are the benefits of good CX for customers, businesses, and society? Let us use a financial institution as an example to present CX's benefits or value propositions (Andreasen et al., 2016; Clatworthy, 2011; Epp \& Price, 2011; Furrer et al., 2016; Hamilton \& Price, 2019; Nasution et al., 2014):

- Customers benefit when products, services, and delivery experiences are designed considering their perspectives. Thus, customer-centred helps in more significant usage and delivery value to customers since now better fit their lives through enlarged relevance, convenience, and affordability.

- Businesses deliver values when customers grow. These values proposition range from a more active account, brand image reputation towards customer loyalty. Thus, a customer-centred view throughout a product and service portfolio often means a better market fit to reach more customer loyalties and retentions (Wetter-Edman, 2011).

- For people: think of society in poverty who now experience enlarged economic development, in other words, families who can afford better education, contribute to the local economy, and save for long term means delivering value at the people level. Thus, the poor have an opportunity to balance incomes and expenses; consequently, economies experience growing and thriving (Furrer et al., 2016; Verhoef et al., 2009).

- Shifting in strategy from a portfolio of products or services that address growth focus on identifying the best customers for products to a portfolio of customers that address growth based on meeting customer needs;

- Shifting from a culture that rewards employees for simply increasing sales to a culture that rewards teams for solving customer issues and deepening customer relationships;

- Shifting from an organisational structure in which teams operate in product silos and interact with the functions only when required to get a product to market.

According to Kim, Kim and Miner (2009), a more favourable organisational structure is one in which business units are connected across functions by employees or task forces that rally diverse functions around customer needs and segments.

\section{Customer Value Drivers for a CX Project}

The customer value drivers depend on the customer lifecycle stages. Ordinarily, respecting the different models available in several pieces of literature, a customer lifecycle framework encompasses eights steps (Andreassen et al., 2016; Clatworthy, 2011; Johnston \& Kong, 2011; Hamilton \& Price, 2019):

g) Latent needs: the potential customer is not aware of the offerings.

h) Felt needs: the potential to recognise that her/his need can be addressed through a product or service offering.

i) Search: the potential customer searches for various product or service options that can adequately address her/his needs.

j) Select: the potential customer decides to go ahead with a product or service offering.

k) Onboard: the customer interacts with a company through various onboarding processes such as filling forms, buying or renting products or services, training on how to use products or services, etc.

1) Use: the customer begins to engage with the product or service and learning and creating new uses and benefits.

m) Migrate up: the customer decides to upgrade her/his profile, increasing her/his consumption rate or buying multiple offerings, then, customer relationship management (CRM) begins to be deployed to reach the customer (Berry \& Carbone, 2007).

n) Migrate down: the customer reduces or stagnates his/her portfolio consumption; hence, data analysis should be 
required to taking an equivalent decision concerning the customer profile status.

The customer value drivers depend on these stages in the customer lifecycle because customers have different needs and expectations from an organisation (Gentile, Spiller, \& Noci, 2007). On the one hand, when these needs and expectations, which can also be considered as value drivers, it increases customer satisfaction (Prahalad \& Ramaswamy, 2004). On the other hand, they are not reached, it increases customer pain points and reduces satisfaction (Pullman \& Gross, 2004). By and large, customers feel pain when a certain value-driver relevant to them is not a part of their CX at any stage of the lifecycle. The main nine customer value drivers are (Berry, Carbone, \& Haeckel, 2002; Furrer et al., 2016; KPMG Report, 2019; Meyer \& Schwager, 2007; Sujata et al., 2015; Walls et al., 2011):

a) Speed: the end-to-end lifecycle time and also the process-stage time required by a given customer to complete a buy or rent.

b) Convenience: the ability of customers to buy or rent a product or service with a company with minimal disruption to their personal and professional routines.

c) Risk: The risk of not buying or rent a product or service or the risk of wasting money on a product or service which does not have benefits, or also, the risk of the customer not receiving the product or service in his/her home (Szymanski \& Henard, 2001).

d) Relationship: the ability of customers to engage with a company's employees, discuss their benefits and decisions, and receive information and guidance from products or services more suitable for their routine (Brakus, Schmitt, \& Zarantonello, 2009).

e) Flexibility: the ability of customers to buy or rent a product or service with a company through processes and norms that adapt to their culture, habits, behaviours, power of purchase and time-related references (Nasution et al., 2014).

f) Information: access to easy to understand, unbiased information that helps customers make better choices about products or services (Puccinelli et al., 2009).

g) Cost: the financial, psychological, time and effort of engaging with a company (Johnston, 1999).

h) Emotion and Comfort: the level of physical and emotional comfort customers experience while interacting with a company across the lifecycle (Schmitt, 2003).

It is essential to realise that a critical component of CX design is choosing trade-offs between these value drivers. For instance, a process improvement designed to maximise customer handling capacity at a company might reduce company staffing needs (and hence costs) but might simultaneously lead to a weaker relationship with customers or lowered comfort levels for them (Verhoef et al., 2009). Similarly, there might be a conflict between maximising customer speed and managing financial risk for a company due to fewer due diligence checks. In such situations, a company needs to do leadership and CX managers who should take decisions after carefully assessing the trade-offs (Maklan \& Klaus, 2011). Furthermore, it is helpful to develop a list of CX "non-negotiables" that serve as the baseline for how a company plans to treat its customers and incorporates these processes into the primary "cost of doing business" calculation.

There are five groups of stages in a CX project that occur interactively. Each of these stages is depicted in Figure 1 and explained in detail in Table 1. It is worth advising that not all of these stages can be required for every CX project. For example, specific projects might only need customer research, whereas other might need prototyping. 


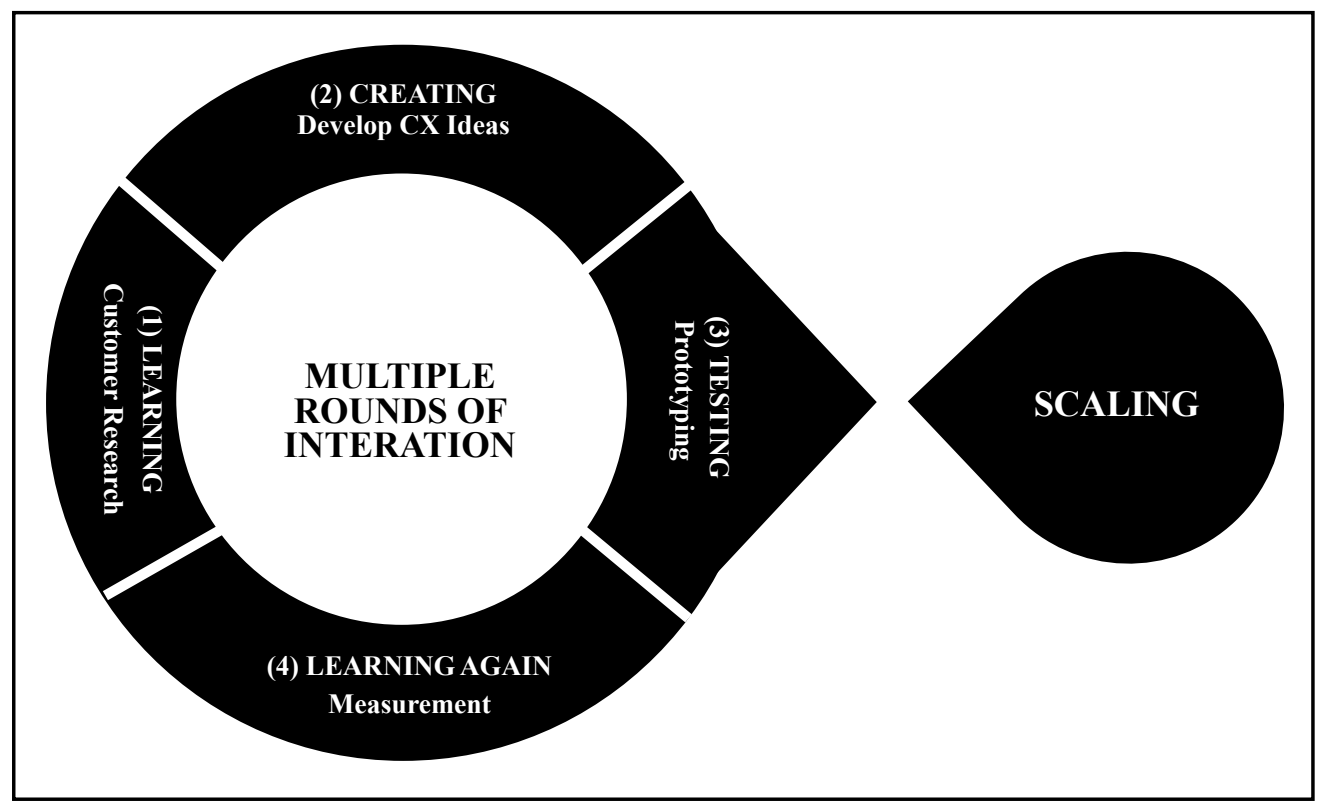

Figure 1. 5 Stages of a CX Project

Source: Adapted by the author, 2020.

Table 1. 5 Stages of a CX Project

\begin{tabular}{|c|c|}
\hline Stages & Description \\
\hline $\begin{array}{l}\text { (1) Learning | Customer } \\
\text { Research }\end{array}$ & $\begin{array}{l}\text { Customer research aims to develop a nuanced understanding of the needs, the financial life, and the } \\
\text { macro-environment within which customers operate. Human-centred design methods are used for this } \\
\text { research within (i) in-depth (one to one) household research settings and (ii) field research methods such } \\
\text { as fly on the wall (FOTW) (Kuehnl, Jozic \& Homburg, 2019). }\end{array}$ \\
\hline $\begin{array}{l}\text { (2) Creating | Develop CX } \\
\text { Ideas }\end{array}$ & $\begin{array}{l}\text { Next, these research insights are translated into ideas for CX improvements through cross-functional } \\
\text { co-design workshops. Ideas are generated, prioritised, and then converted into plans for implementable } \\
\text { prototypes. These cross-functional teams need to comprise people from customer-facing functions such } \\
\text { as sales, product development, operations, human resource and customer insights (Lin \& Bennett, 2014). }\end{array}$ \\
\hline (3) Testing | Prototype & $\begin{array}{l}\text { High potential ideas are then tested with actual customers through low and medium fidelity prototypes. } \\
\text { This involves creating low-cost solutions for specific parts of large problems and seeing whether } \\
\text { customers respond positively to these changes. Co-design workshops, where cross-functional teams } \\
\text { come together to create solutions, are often used in prototyping. External experts might also be involved } \\
\text { are usually sufficient to get good feedback (Maklan \& Klaus, 2011; Prahalad \& Ramaswamy, 2004; } \\
\text { Sujata et al, 2015). }\end{array}$ \\
\hline $\begin{array}{l}\text { (4) Learning Again | } \\
\text { Measurement }\end{array}$ & $\begin{array}{l}\text { The impact of all prototypes must be measured through a customer feedback survey to assess whether } \\
\text { the CX improvement prototypes added value (based on starting hypotheses). In some cases, it might be } \\
\text { possible to carry out a cost-benefit analysis and determine whether the Return of Investment (ROI) is } \\
\text { positive. Customer satisfaction measurement surveys can be implemented with small samples of } \\
\text { customers but must, usually, be done by independent persons with no stake in the outcome. The } \\
\text { measurement then leads to either scale-up to the need for more research and interactions (KPMG Report, } \\
\text { 2020; Maklan \& Klaus, 2011). }\end{array}$ \\
\hline (5) Scaling $\mid$ Scale Up & $\begin{array}{l}\text { Successful prototypes (product or service) that have performed well on their measurement parameters } \\
\text { are then scaled up across several platforms: physical or virtual (Furrer et al., 2016; Voorhees et al., } \\
\text { 2017). }\end{array}$ \\
\hline
\end{tabular}

Source: Adapted by the author, 2020.

CX projects require a few key elements for supported the practice. These operating practices are essential to achieve great results. Four elements are equally important (Gentile, Spiller, \& Noci, 2007; Johnston \& Kong, 2011; Hamilton \& Price, 2019; Verhoef et al., 2009):

a) CX needs leadership support $-\mathrm{CX}$ projects require robust top management support to remain true to their mission and to guarantee that $\mathrm{CX}$ remains a priority when faced with difficult trade-offs;

b) Cross-functional involvement: CX projects will cut across different functions-product, sales, 
operations - and will require the formation of cross-functional teams for executing. These projects will require to have a full-time CX manager at the very least (Kim, Kim, \& Miner, 2009);

c) Budgets - CX projects need separate budget heads, particularly in cases where the value does not accrue to any single business area. A separated budget is also required for CX professionals;

d) Performance management $-\mathrm{CX}$ projects need to be linked to Key Performance Indicators (KPIs), both at an organisational and team member performance administration level. Without this, it is difficult to achieve large-scale performance and proper institutionalisation of CX projects.

\section{Describing the 5 Stages of the CX Project}

The first stage is customer research through human-centred design methods. In summary, four processes are carried out to develop relevant insights to achieve a deep understanding of customers: research design, recruit participants, carry out the research and synthesis. Process number one encompasses designing and refining instruments focused on customer pain points and opportunities for improving CX (Andreassen et al., 2016). For Lin and Bennett (2014), the scope of the instrument requires asking customers about the whole lifecycle of needs and flows rather than focusing on just interactions. There are three primary methods:

a) Household research sessions design a nuanced comprehension of the critical concerns and want in customers' lives and contacts.

b) Field observation sessions to figure out the direct and hidden experiences and needs of behaviours.

c) Workshops to capture customer information concerning actionable ideas and project opportunities.

Process number two comprises recruiting an appropriate number and type of customers and potential customers to execute the user research. Depending on the scope of the study, between 15-50 customers are usually a good number of participants to generate a profound insight. User research requires a carefully curated set of participants. Then, recruiting such participants for individual and group research sessions can sometimes be a challenge given the $2-3$ hours commitment sought. Process number three aims to carry out the research. It is required to have someone who can speak the local language in the research team (Payne, Storbacka, \& Frow, 2008; Voorhees et al., 2017). User-centred research relies heavily on observations of subtle cues, and this language barrier tends to be mitigated. In process number four, the research team should organise a regular synthesis and discussion. All field data is understood and coded into categories to garner critical insights into the customer's pain, CX improvement opportunities, and constraints. Co-design workshops are a very effective mechanism for such synthesis (Prahalad \& Ramaswamy, 2004).

The second stage aims to develop CX ideas. For Barwitz and Maas (2018), creating practical ideas for CX improvement based on research insights is best executed using a few fundamental operation principles:

- Engagement across functions can assist professionals with deep experience in different aspects of customer management, for instance, analytics, marketing, operations, sales, and so forth (Kim, Kim, \& Miner, 2009). Therefore, the CX ideas should be designed in a manner that involves cross-functional expertise.

- Prevent premature critique; it means many CX ideas will run counter to prevailing wisdom, and it is relevant that they are given thoughtful attention rather than early criticism. Having senior management support for this is critical (Hamilton \& Price, 2019).

- Clear parameters aim to rank CX ideas to every idea that gets rated on a well-defined set of metrics rather than some being chosen or dropped subjectively (KPMG Report, 2020).

- Stories communicate better; in other words, writing down CX ideas as short stories, with pictures and a 100-150 word description, is a better way to encourage thoughtful debate rather than short blurbs, which ten do get interpreted differently by different people (Voorhees et al., 2017).

This stage requires that the CX team manages vital challenges. For Gentile, Spiller and Noci (2007) and Johnston (2011), it is standard operating for good CX improvement ideas, but they are quickly addressed with appropriate participation and mindsets. First of all, ensuring that CX idea generation sessions create and track truly transformational ideas to remain on the list for future innovations. Then, make sure that $\mathrm{CX}$ idea generation sessions have broad collaborative participation with stakeholders across different functions-particularly the process value chain actors - involved in delivering innovative products or services to customers. Finally, research and ideation CX employees require to clearly articulate an idea and its value proposition to senior management even though the idea is based on real customer insight. For Kuehnl, Jozic and Homburg (2019), the ideation is when CX teams create a solution and brainstorm about its basic working mechanics, such as resources required, action to be taken, and team formation. 
The prototyping is the third stage. Overall, a prototype is an early version of a solution that may not have all the details of a fully fleshed-out solution. The objective is to take promising CX ideas and then test them with customers and reach rapid answers so that, after a couple of iterations, the CX improvement may be formally included in the prototype as learning (Maklan \& Klaus, 2011). Prototypes can be about new products, new services, or new processes or could target changes to existing products, services, and processes. The prototyping stage should be planned, keeping in mind the shortest amount of time (as well as budget) needed to convincingly provide answers to the hypothesis (Andreassen et al., 2016; Furrer et al., 2016; Kim, Kim, \& Miner, 2009; Wetter-Edman, 2011). CX prototyping projects typically encompass five processes; see Table 2.

Table 2. Prototyping processes

\begin{tabular}{ll}
\hline Processes & Description \\
\hline (1) Plan & To conclude the prototype, the key CX improvement hypothesis should be tested, conclude sample sizes, locations, \\
& make a list of requirements and supplies, budgets, timelines and ownership. \\
(2) Design & $\begin{array}{l}\text { It requires design collateral, artefacts, processes, or training material that might need in implementing the } \\
\text { prototype. Depending on the complexity of the requirement, external support from partnership organisations can be } \\
\text { useful to assist in the design process. }\end{array}$ \\
(3) Production & $\begin{array}{l}\text { Depending on what is being prototyped, one may need to procure or produce certain collateral or artefacts. For } \\
\text { instance, training manuals might also need to be created or purchased. }\end{array}$ \\
(4) Implement & $\begin{array}{l}\text { Once planning, design and production are complete, the CX prototype will be either centrally or locally (with a few } \\
\text { customers) run for a few days or weeks until the target sample size of customers is reached. A few field staff may }\end{array}$ \\
& $\begin{array}{l}\text { need to be trained to help implement the prototype on the field. } \\
\text { (5) Measure }\end{array}$ \\
\hline
\end{tabular}
Source: Adapted by the author, 2020.

It is relevant to draw the attention of relevant aspects concerning CX prototyping. First, understanding "why" the purpose (or benefit) of the prototype by clearly thinking it to customer value drivers. Second, prototypes are not pilots; that is, pilots tend to be small-scale implementations of a whole process or service, whereas prototypes tend to test specific components of services or processes with a small target audience (Furrer et al., 2016; Kim, Kim, \& Miner, 2009; Wetter-Edman, 2011). Third, considering the user experience perspective in the prototype interactions in order to provide relevant feedback. Fourth, fast and cheap; in other words, speed prototyping can be more valuable than expecting "perfection" before launching a prototype (Hamilton \& Price, 2019). Even low-fidelity prototypes may yield very useful learning and insights about what can be enhanced in the CX project. Fifth, prototyping requires assessment and approval parameters that are less stringent than those used for standard projects or even pilots. Lastly, the prototyping requires a separate budget for regularly enhancing the CX prototype after testing sessions (Kuehnl, Jozic, \& Homburg, 2019).

The CX prototypes should be evaluated critically to see if they are improving CX. This is the fourth stage, in other words, measuring and sharing results. In a small number of cases, it also is useful to measure the financial ROI of prototyping through improved customer loyalty and purchase behaviour (KPMG Report, 2020). For Maklan and Klaus (2001), measurement has the goal of getting rapid feedback from customers exposed to prototypes to modify and continuously adapt to the results. According to Verhoef et al. (2009), prototype evaluation and measurement can be conducted through multiple methods such as customer surveys, interviews, focus group discussions, analysis of customer data to observe before-after prototype indicators. For Walls et al. (2011), it is crucial selecting methods based on the nature of the prototype and customer characteristics. Hence, for creating reliable scale-up successful prototypes, five processes need to be designed:

a) Frame measurement goal: it involves listening to key hypotheses of how the prototype would lead to certain sorts of CX improvements and the parameters that would require to be measured to assess whether or not CX enhances have been achieved (Epp \& Price, 2011).

b) Instrument design: it encompasses designing an appropriate research instrument to measure the impact of the prototype. Depending on the indicators being started tested through the prototype, the tool could be a customer survey, a focus group, customer datasets that exist in an organisation or even an interactive customer session (Gentile, Spiller, \& Noci, 2007).

c) Measurement tool implementation: during the implementation phase, the CX manager decides the sample of customers to survey, such as administering an answer survey to a suitable percentage of customers who might have been exposed to prototypes or not or by querying the customer database to obtain certain areas of data and 
information that are of interest (Johnston \& Kong, 2011).

d) Analysis and feedback: both comprise appropriately formatting the data gathered through such survey of focus groups, structuring analyses, and drawing insights around whether the prototype is performing successfully and is reaching the CX improving objectives envisioned or not (Payne, Storbacka, \& Frow, 2008).

e) Recommending scale-up: finally, the CX manager creates recommendations regarding how successful prototypes should be scaled. This involves creating presentations that recommend certain features of the prototypes for scaling up and back up the suggestions with measurement data. However, not all measurements will reveal the successful performance of prototypes. Some prototypes might need to be rejected outright, others modified, and still, others scaled back (Nasution et al., 2014).

Producing successful CX prototypes is not enough. If they are not accepted by a large number of the company's customers, value is lost, and many of them may continue to have a suboptimal CX. The key to large adoption is a robust scaling-up process that takes successful prototypes and ensures that they get tested and implemented at the company. By and large, a company should create a reliable process to scale up successful prototypes (Kuehnl, Jozic, \& Homburg, 2019). The scaling up could have the following three processes, which be executed iteratively by our management teams. First, craft CX scales up the company's strategy; in other words, a clear strategy and process for scaling up successful prototypes on a regular basis will require to be designed. The strategy should be crafted by senior management and, in creating this scale-up strategy, different stakeholders across the company might have distinct concerns that need to be considered and analysed.

Then, make CX prototypes "more scalable" because CX prototypes are designed to test key CX hypotheses quickly and effectively. They often employ "hacks" or workarounds that are not scalable or cost-efficient. If the prototypes prove successful, then almost always, they need to be re-purposed to a specification that is efficient, fits within broader company processes, is reliable, and scalable. Lastly, pitch effectively. Even with an ongoing CX scale-up strategy framework and scalable prototypes, CX teams require to prepare strong pitches for senior management for their projects to be favourably evaluated and for organisational resources to be committed to scaling them up. CX teams can make use of tools such as the Business Model Canvas to create compelling pitches and increase the scale-up rate for prototypes (Nasution et al., 2014).

\section{Final Considerations}

In essence, experimental marketing strategies have been designed by companies in order to attract customers to interact and be engaged with their product or service and particularly designed to make the customers experience favourable attitudes, either through direct interaction or indirect interaction with the company through intermediaries that connect them. These communications will result in $\mathrm{CX}$ with the organisation. These interactions can be organised into three steps of customer changing experience: pre-consumption, actual and post-consumption. In fact, the CX encompasses a psychological construct, which is a holistic, subjective attitude resulting from customer contact with the company and which include different levels of customer engagement (Gentile, Spiller, \& Noci, 2007; Pine \& Gilmore, 1999).

In effect, these stimulate communication with the customer and offers six distinct answers which construe the $\mathrm{CX}$, established as sensorial and physical, emotional, and affective, cognitive, pragmatic, lifestyle, and relational (Schmitt, 1999, 2003). Hence, those interactions and customer involvement accrue as the accumulation of knowledge, value, and perceived quality in every phase of the experience process resulting in the expanded likelihood of customers determining an emotional connection with the offering. The merge of CXs throughout of consumption process and whether or not cycle consumption was built will then form the layer of accumulated CX (Meyer \& Schwager, 2007). 


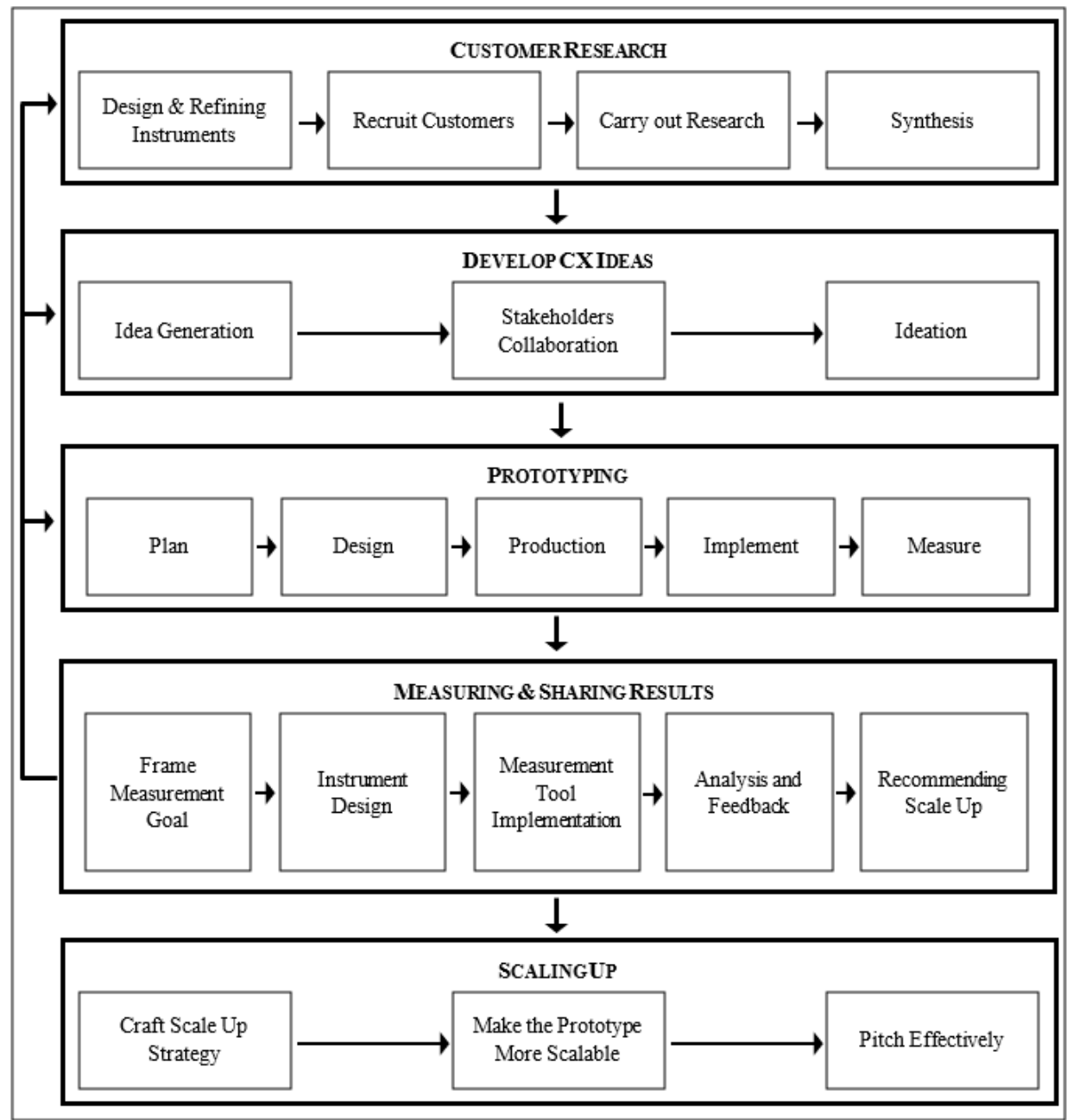

Figure 2. CX Framework

Source: Adapted by the author, 2020.

Examining a significant number of CX pieces of literature, we recognised a lack of structured instrument to guide CX managers and teams to identify the main customer value drivers and then organise an experience to customers when they interact with companies in pre-consumption, actual, and post-consumption (lifecycle) phases (Berry, Carbone, \& Haeckel, 2002). Thus, this theoretical article had the purpose of approaching the major customer value drivers and describing the five stages required to assist CX professionals in conceiving, design and implement CX improvement projects. This paper depicted nine significant customer value drivers for companies focus on their CX projects: speed, convenience, risk, relationship, flexibility, information, cost, and emotion and comfort. Furthermore, five stages were presented and detailed to achieve the CX projects goals (Berry, Carbone, \& Haeckel, 2002; Furrer et al., 2016, KPMG Report, 2019; Meyer \& Schwager, 2007; Sujata et al., 2015; Walls et al., 2011), see Figure 2.

a) Conduct immersive field research to understand challenges in the current CX.

b) Ideate and generate solutions to CX challenges identified through customer research.

c) Based on the CX ideas generated, design and run small scale prototypes that enhance different forms of CX.

d) Measure results of CX prototypes and, then, make the decision which ones to move forward at scale with or without changes.

e) Scaling up successful CX prototypes across the company and product lines.

Hence, a CX manager needs to design a CX improvement project based on customer lifecycle and customer value drivers to deliver benefits to the company and customers (or users). 
Nevertheless, for conceiving, designing, and implementing CX improvement projects, an organisation depends on the adoption of a CX culture. CX culture means a company should implement customer-centricity (or human-centred) orientation (Pine \& Gilmore, 1999). It is relevant that beyond specific CX ideas or prototypes, customer-centric becomes a vital part of a company's culture, in other words, shaping strategy, organisational structure, staffing, skilling and spirit (Berry \& Carbone, 2007). Overall, an organisation can adopt a more customer-centred culture through eight kinds of initiatives: make CX strategic, integrate CX with leadership, make CX visible, integrate $\mathrm{CX}$ with training and capacity development, connect $\mathrm{CX}$ with performance management, integrate CX with work, build a CX platform (practices) and dedicate budgets to carry out CX projects (Verhoef et al., 2009).

In effect, the entire organisation requires to be engaged across different functions to deal with challenges such as creating a CX mindset, changing the management processes and designing tangible and measurable performance metrics for employees in different roles within a company. For future studies relate to CX, two subjects can require a certain devotion for researchers: the applications of the CX project framework in different types of services areas in order to verify the primary challenges in carrying out, and the impact of a customer-centred culture to achieve high performance in CX projects.

\section{References}

Andreassen, T. W., Kristensson, P., Lervik-Olsen, L., Parasuraman, A., McColl-Kennedy, J. R., Edvardsson, B., \& Colurcio, M. (2016). Linking Service Design to Value Creation and Service Research. Journal of Service Management, 27(1), 21-29. https://doi.org/10.1108/JOSM-04-2015-0123

Barwitz, N., \& Maas, P. (2018). Understanding the Omnichannel Customer Journey: Determinants of Interaction Choice. Journal of Interactive Marketing, 43, 116-133. https://doi.org/10.1016/j.intmar.2018.02.001

Berry, L. L., \& Carbone, L. P. (2007). Build Loyalty Through Experience Management. Quality Progress, 40(9), $26-32$.

Berry, L. L., Carbone, L. P., \& Haeckel, S. H. (2002). Managing the Total Customer Experience. MIT Sloan Management Review, 43(3), 85-89.

Brakus, J. J. S., Schmitt, B. H., \& Zarantonello, L. (2009). Brand Experience: What is it? How is it Measured? Does it affect Loyalty? Journal of Marketing, 73(3), 52-68. https://doi.org/10.1509/jmkg.73.3.52

Carbone, L. P., \& Haeckel, S. H. (1994). Engineering Customer Experiences. Marketing Management, 3(3), $8-19$.

Clatworthy, S. (2011). Service Innovation through Touch-Points: Development of an Innovation Toolkit for the First Stages of New Service Development. International Journal of Design, 5(2), 15-28.

Epp, A. M., \& Price, L. L. (2011). Designing Solutions Around Customer Network Identity Goals. Journal of Marketing, 75(2), 36-54. https://doi.org/10.1509/jm.75.2.36

Furrer, O., Rodoula, D. S., Tsiotsou, H., \& Liu, B. S. (2016). A framework for Innovative Service Design. The Service Industries Journal, 3(9-10), 452-471. https://doi.org/10.1080/02642069.2016.1248420

Gentile, C., Spiller, N., \& Noci, G. (2007). How to Sustain Customer Experience: An Overview of Experience Components that Co-Create Value with the Customer. European Management Journal, 25(5), 395-410. https://doi.org/10.1016/j.emj.2007.08.005

Grace, D., \& O'Cass, A. (2004). Examining Service Experiences and Post-Consumption Evaluations. Journal of Services Marketing, 18(6), 450-461. https://doi.org/10.1108/08876040410557230

Hamilton, R., \& Price, L. L. (2019). Consumer Journeys: Developing Consumer-Based Strategy. Journal of the Academy of Marketing Science, 47, 187-191. https://doi.org/10.1007/s11747-019-00636-y

Holbrook, M. B., \& Hirschman, E. C. (1982). The Experiential Aspects of Consumption: Consumer Fantasies, Feelings, and Fun. Journal of Consumer Research, 9(10), 132-140. https://doi.org/10.1086/208906

Johnston, R. (1999). Service Transaction Analysis: Assessing and Improving the Customer's Experience. Managing Service Quality, 9(2), 102-109. https://doi.org/10.1108/09604529910257876

Johnston, R., \& Kong, X. (2011). The Customer Experience: A Road-map for Improvement. Managing Service Quality, 21(1), 5-24. https://doi.org/10.1108/09604521111100225

Kim, J. Y., Kim, J. Y., \& Miner, A. S. (2009). Organizational Learning from Extreme Performance Experience: The Impact of Success and Recovery Experience. Organization Science, 20(6), 958-978. 
https://doi.org/10.1287/orsc.1090.0439

KPMG Report. (2019). The New Competitive Advantage: Customer Experience Excellence. Retrieved April 15, 2020, from https://assets.kpmg/content/dam/kpmg/ro/pdf/2019/customer-experience-lq.pdf

Kuehnl, C., Jozic, D., \& Homburg, C. (2019). Effective Customer Journey Design: Consumers' Conception, Measurement, and Consequences. Journal of the Academy of Marketing Science, 47(3). https://doi.org/10.1007/s11747-018-00625-7

Lin, Z., \& Bennett, D. (2014). Examining Retail Customer Experience and the Moderation Effect of Loyalty Programmes. International Journal of Retail \& Distribution Management, 42(10), 929-947. https://doi.org/10.1108/IJRDM-11-2013-0208

Maklan, S., \& Klaus, P. P. (2011). Customer Experience: Are We Measuring the Right Things? International Journal of Market Research, 53(6), 771-792. https://doi.org/10.2501/IJMR-53-6-771-792

Meyer, C., \& Schwager, A. (2007). Understanding Customer Experience. Harvard Business Review, 85(2), 116.

Nasution, R. A., Sembada, A. Y., Miliani, L., Resti, N. D., \& Prawono, D. A. (2014). The Customer Experience Framework as Baseline for Strategy and Implementation in Service Marketing. Procedia - Social and Behavioral Sciences, 148, 254-261. https://doi.org/10.1016/j.sbspro.2014.07.041

Parasuraman, A., Zeithaml, V. A., \& Malhotra, A. (2005) E-S-QUAL: A Multiple-item Scale for Assessing Electronic Service Quality. Journal of Service Research, 7(3), 213-233. https://doi.org/10.1177/1094670504271156

Payne, A., Storbacka, K., \& Frow, P. (2008). Managing the Co-Creation of Value. Journal of the Academy of Marketing Science, 36(1), 83-96. https://doi.org/10.1007/s11747-007-0070-0

Pine, B. J. I. I., \& Gilmore, J. H. (1998). Welcome to the Experience Economy. Harvard Business Review, 76(4), $97-105$.

Pine, J., \& Gilmore, J. H. (1999). The Experience Economy: Work is Theatre \& Every Business a stage. Harvard Business School Press: Boston.

Prahalad, C. K., \& Ramaswamy, V. (2004). Co-Creation Experiences: The Next Practice in Value Creation. Journal of Interactive Marketing, 18(3), 5-14. https://doi.org/10.1002/dir.20015

Puccinelli, N. M., Goodstein, R. C., Grewal, D., Price, R., Raghubir, P., \& Stewart, D. (2009). Customer Experience Management in Retailing: Understanding the Buying Process. Journal of Retailing, 85(1), 15-30. https://doi.org/10.1016/j.jretai.2008.11.003

Pullman, M. E., \& Gross, M. A. (2004). Ability of Experience Design Elements to Elicit Emotions and Loyalty Behaviors. Decision Science, 35(3), 551-578. https://doi.org/10.1111/j.0011-7315.2004.02611.x

Rowley, J. (1999). Measuring Total Customer Experience in Museums. International Journal of Contemporary Hospitality Management, 11(6), 303-308. https://doi.org/10.1108/09596119910281801

Schmitt, B. (1999). Experiential Marketing. Journal of Marketing Management, 15(1-3), 53-67. https://doi.org/10.1362/026725799784870496

Schmitt, B. (2003). Customer Experience Management: A Revolutionary Approach to Connecting with your Customer. New Jersey: Wiley and Sons.

Sujata, J., Sanjay, B., Kiran, R., \& Rohan, A. (2015). Towards Greater Customer Experience: Role of Network Parameters on Key Business Drivers. ARPN Journal of Engineering and Applied Sciences, 10(3).

Szymanski, D. M., \& Henard, D. H. (2001). Customer Satisfaction: A Meta-Analysis of the Empirical Evidence. Journal of the Academy of Marketing Science, 29(1), 16-35. https://doi.org/10.1177/0092070301291002

Verhoef, P. C., Lemon, K. N., Parasuraman, A., Roggeveen, A., Tsiros, M., \& Schlesinger, L. A. (2009). Customer Experience Creation: Determinants, Dynamics, and Management Strategies. Journal of Retailing, 85(1), 31-41. https://doi.org/10.1016/j.jretai.2008.11.001

Voorhees, C. M., Fombelle, P. W., Gregoire, Y., Bone, S., Gustafsson, A., Sousa, R., \& Walkowiak, T. (2017). Service Encounters, Experiences, and the Customer Journey: Defining the Field and a Call to Expand our Lens. Journal of Business Research, 79, 269-280. https://doi.org/10.1016/j.jbusres.2017.04.014

Walls, A., Okumus, F., Wang, Y., \& Kwun, D. (2011). Understanding Customer Experience: An Exploratory Study of Luxury Hotels. Journal of Hospitality Marketing and Management, 20(2), 166-197. 
https://doi.org/10.1080/19368623.2011.536074

Wetter-Edman, K. (2011). Service Design: A Conceptualization of an Emerging Practice. Licentiate thesis, University of Gothenburg, Gothenburg, Sweden.

\section{Copyrights}

Copyright for this article is retained by the author, with first publication rights granted to the journal.

This is an open-access article distributed under the terms and conditions of the Creative Commons Attribution license (http://creativecommons.org/licenses/by/4.0/). 